Publisher homepage: www.universepg.com, ISSN: 2663-7804 (Online) \& 2663-7790 (Print)

https://doi.org/10.34104/ajeit.020.042053

Australian Journal of Engineering and Innovative

Technology

Journal homepage: www.universepg.com/journal/ajeit

\title{
Arsenic Removal from Aqueous Solutions Using Carbon Embedded Silica and Zeolite: Column Adsorption Studies
}

\author{
Tariqul Islam ${ }^{1,2} *$ and Changsheng Peng ${ }^{1,3}$
}

${ }^{1}$ The Key Lab of Marine Environmental Science and Ecology, Ministry of Education, Ocean University of China, Qingdao 266100, China; ${ }^{2}$ Department of Agricultural Construction and Environmental Engineering, Sylhet Agricultural University, Sylhet-3100, Bangladesh; and ${ }^{3}$ School of Environment and Chemical Engineering, Zhaoqing University, Zhaoqing 526061, China.

*Correspondence: tariqul.acee@sau.ac.bd

\section{ABSTRACT}

Column adsorption of the As (III) \& As (V) using rice husk mediated carbon embedded silica (CES) and zeolite (Z-RHA) has been proved promising technique rather than the other conventional methods. The present work investigates the adsorption capability of newly manufactured CES and Z-RHA to remove As (III) \& As (V) from aqueous solutions. Fourier transform infrared spectroscopy (FTIR), X-ray diffraction (XRD), Scanning electron microscope (SEM), Energy dispersive X-ray (EDX), and Transmission electron microscopy (TEM) analysis have been investigated for the characterization of synthesized materials. The effects of different parameters like initial concentrations, column diameter, column height, particle size distribution have been investigated. Maximum removal efficiency of CES adsorbents for As (III) is $98 \%$ and for As (V) is $85 \%$, and of Z-RHA for As (III) is $95 \%$ and for As (V) is $92 \%$. To describe the adsorption behavior the Langmuir and Freundlich isotherm models as well as to kinetics models like Adam-Bohart, Thomas, and Yoon Nelson model were applied. Finally, to dispose of the rice husk mediated adsorbents after arsenic treatment solidification has been done.

Keywords: Adsorption, Carbon embedded silica, Zeolite, Trace elements, Aqueous solutions, and Arsenic.

\section{INTRODUCTION:}

Arsenic (As) considered overshadowed in the applied science due to its notoriety and toxicity in nature (Mohan and Pittman, 2007). Arsenic contamination in ground water as well as in potable water is causing serious health hazards and environmental problems in many regions over the world (Biterna et al., 2010). Almost 21 countries over the world including Argentina, Bangladesh, Pakistan, India, China, U.S.A. etc. are exposed to As contamination by drinking As conta-

UniversePG I www.universepg.com minated water (Sohel et al., 2009; Li et al., 2011; Islam et al., 2018). Toxicity of As effect adversely on human health gradually after long term ( 5 to 10 years) consumption of As contaminated water. Treatment of As contaminated water may elucidate the adverse effect of As on human health. There are several techniques of filtration or removal of As, but most of them are not affordable for the poor affected people. Consequently, it is urgent to find a low-cost technology to remove As from drinking water (Antonio et al., 2009). 
As are found in environment both of organic and inorganic forms. Groundwater contains inorganic form of As which is more toxic than organic form (Dinesh et al., 2007). The major sources of the As are power plants powered by coal plants, vegetation burning, volcanic activity and human activities etc. High level of As has been detected in groundwater from different area over the world (Bangladesh, India, Taiwan etc.) due to natural geological contamination. According to World health organization (WHO) thousands of people from Vietnam to Pakistan died of cancer due to As contamination by drinking water. Scott et al. (2010) reported that the cardiovascular and mental health problems are occurred due to the exposure of As. All over the world people are consuming the drinking water with higher concentrations of As than the recommended limit of WHO $10 \mathrm{mg} / \mathrm{L}$.

Arsenate $[\mathrm{As}(\mathrm{V})]$ and arsenite $[\mathrm{As}(\mathrm{III})]$ are the two most predominant inorganic species of As. As(III) species are more toxic than $\mathrm{As}(\mathrm{V})$, subsequently removal of As(III) by conventional physiochemical treatment methods is more difficult than removal of As(V) (Dinesh et al., 2007). There are different available As remediation technologies including ion exchange, filtration, precipitation, coagulation, membrane process, bioremediation etc. (Antonio et al., 2009). Most of the available technologies developed for industrial level and cost is high. Many researchers over the world tried to use naturally occurring materials with different modification as adsorbent to remove heavy metals. Capacity of the adsorbents depends on the nature of the heavy metal ions, concentrations of pollutants, $\mathrm{pH}$, reaction/contact time and the characteristics of the materials used as adsorbents. Variety of agricultural materials including wheat husk, rice husk, tree bark, coconut shells, tea waste, maize corn cob, orange peel etc. have been used to investigate for removing different metals from aqueous solutions (Ali et al., 2017; Saju et al., 2020; Asif \& Chen, 2017). However, very few studies were found on the use of rice husk as adsorbents to remove As from aqueous solutions (Nurul Amin et al., 2006).

Present work has been elucidating the potential of rice husk mediated adsorbents (CES and Z-RHA) to remove both of As (III) and As (V) species from water.
The study has been carried out by column adsorption study. The rice husk is easily available agricultural waste with no or very low price. So, it has a great opportunity to use as adsorbents. Moreover, the performances of adsorbents in present adsorption studies has been investigated by observing the effect of various parameters like initial metal concentrations, column height and diameter, and particle size of adsorbents.

\section{MATERIALS AND METHODS:}

\section{Adsorbent preparation}

Collection of rice husk and preparation of rice husk ash (RHA) - Rice husk (RH) was collected from one of the village markets with negligible cost. Collected $\mathrm{RH}$ was sorted to separate from foreign materials like dust, broken parts of rice shoots and roots, stones etc. followed by sieving and washing under running tap water. Finally, after washing with distilled water the RH sample were dried in room temperature to remove the moisture present on the surface of the husk. Due to remove the metal impurities presence in the $\mathrm{RH}$ samples were treated with hydrochloric acid. Then the treated husks were stirred with sodium hydroxide to remove the excess acid. Concurrently, the treated $\mathrm{RH}$ was thoroughly washed again by distilled water to remove both of acid and alkali from the surface of $\mathrm{RH}$ (Arenas et al., 2017). After drying the rice husk ash (RHA) was produced by pyrolyzing the $\mathrm{RH}$ at the temperature from $500^{\circ} \mathrm{C}$ to $700^{\circ} \mathrm{C}$ for $5 \mathrm{hrs}$ in a muffle furnace to remove the excess organic contents. Then the RHA was stored in sterile zip-lock bag for further use. Previously, it has been reported that acid treatment, calcination and pyrolisis reactivity and obtained major portion of silica (Banerjee et al., 2017).

Preparation of Z-RHA - Zeolite RHA was prepared from the sodium silicate $\left(\mathrm{Na}_{2} \mathrm{SiO}_{3}\right)$ obtained by RHA. Firstly, seed and feedstock gel were prepared from the $\mathrm{Na}_{2} \mathrm{SiO}_{3}$ by mixing with sodium alluminate $\left(\mathrm{NaAlO}_{2}\right)$. A homogeneous seed gel was prepared by mixing $\mathrm{Na}_{2} \mathrm{SiO}_{3}$ obtained rice husk with $\mathrm{NaAlO}_{2}$ with distilled water under continuous agitation (Banerjee et al., 2017). Prepared gel was left at ambient temperature upto $24 \mathrm{hrs}$ for aging. Consequently, homogeneous gel of $\mathrm{Al}_{2} \mathrm{O}_{3}: 10 \mathrm{SiO}_{2}$ was formed as seed gel. As well as, 
feedstock gel was prepared by following same procedure without any aging. Then the feedstock gel and seed gel were mixed and stirred vigorously to make a homogeneous mixture and again kept in room temperature for $24 \mathrm{hrs}$ for aging. Additionally, the aged solution was crystallized at $100^{\circ} \mathrm{C}$ for another 24 hrs in room temperature. Finally, the prepared sample were washed and dried before further analysis (Goyal et al., 2005).

Preparation of CES - CES was prepared from the sodium silicate obtained from RHA after digestion in the solution of $\mathrm{NaOH}$. RHA was digested with $\mathrm{NaOH}$ solution for $1 \mathrm{hr}$ at $80^{\circ} \mathrm{C}$ temperature to form the silica to $\mathrm{Na}_{2} \mathrm{SiO}_{3}$. Then the alkaline solution obtaining $\mathrm{Na}_{2} \mathrm{SiO}_{3}$ acidifies with phosphoric acid $\left(\mathrm{H}_{3} \mathrm{PO}_{4}\right)$ to neutralize the $\mathrm{pH}$ and form silicic acid (Totlani et al., 2012). Silicic acid is a chemical compound including silicon, hydrogen and oxygen as well it is the hydrate of $\mathrm{SiO}_{2}$. Due to the heating, they lose water to precipitate silica gel as an active form of $\mathrm{SiO}_{2}$. The partially unburnt carbon present in the RHA was made a duel substrate like CES including mesoporous silica and partially activated carbon (Totlani et al., 2012). Finally, the samples were kept at $100^{\circ} \mathrm{C}$ for $24 \mathrm{hrs}$ and preserved for further analysis. The detail procedure was reported previously by Shelke et al. (2010).

\section{Fixed bed column setup}

A column was used to conduct continuous flow adsorption experiments. The column was made by transparent plastic glass with 2.5 and $5 \mathrm{~cm}$ inside diameter and 1.5 meter height. A $0.5 \mathrm{~mm}$ sieve was set at the bottom of the column to support the adsorbent media (RHA, CES, and Z-RHA)in the column (Asif \& Chen, 2017). A wire was also attached with the sieve to move the sieve in upward or downward direction to maintain the height of the column. A peristaltic pump has been used for injecting the polluted solution with required rate. Fig 1 shows the schematic diagram of experimental setup of the fixed bed column.

\section{Column adsorption studies}

The adsorption isotherm studies of the metal ions by using manufactured novel RHA, CES and Z-RHA adsorbents were carried out by using the manufactured column filter.

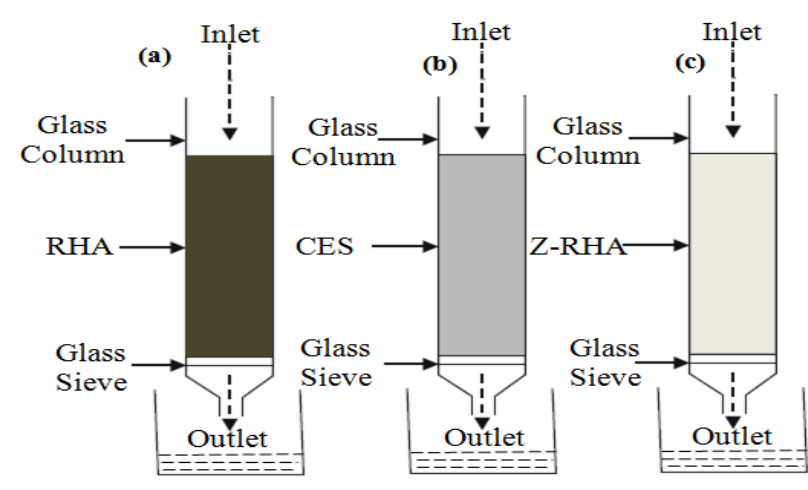

Fig 1: Schematic diagram of the experimental setup for the fixed bed of (a) RHA, (b) CES, and (c) Z-RHA.

The concentrations of the metals were analyzed by atomic absorption spectrophotometer (AAS) to detect the initial and final concentrations of metal ions. The percentages of metal removal, and adsorption capacity at equilibrium phase $\mathrm{q}_{\mathrm{e}}(\mathrm{mg} / \mathrm{g})$ were calculated as:

$$
\% \text { Metal Removal }=\frac{\mathrm{Co}-\mathrm{Ce}}{\mathrm{Co}} \times 100
$$

Where, $C_{0}$ denotes initial concentrations and $C_{e}$ denotes equilibrium concentrations of metal solution. Distilled water was used to do blank before each set of the experiments as control. The adsorption capacity of the unit mass of the adsorbents at equilibrium $q_{e}(\mathrm{mg} / \mathrm{g})$ was calculated by:

$$
q e=\frac{(\mathrm{Co}-\mathrm{Ce}) \mathrm{v}}{w}
$$

where, $v$ is the volume of the metal solution $(\mathrm{ml})$ and $w$ is the weight of the adsorbent $(\mathrm{g})$ added to the volume $v$.

\section{RESULTS AND DISCUSSION:}

Characterization of synthesized adsorbents FTIR analysis - The major peaks in the FTIR spectra (Fig 2a) for RHA at $3475 \mathrm{~cm}^{-1}, 2370 \mathrm{~cm}^{-1}, 1735 \mathrm{~cm}^{-1}, 1143$ $\mathrm{cm}^{-1}, 810 \mathrm{~cm}^{-1}$ and $468 \mathrm{~cm}^{-1}$ are represents the presence of the functional groups, $\mathrm{Si}-\mathrm{OH}, \mathrm{O}=\mathrm{C}=\mathrm{O}$, $\mathrm{C}=\mathrm{O}, \mathrm{Si}-\mathrm{O}-\mathrm{Si}, \mathrm{C}-\mathrm{H}$ and $\mathrm{C}-\mathrm{Cl}$ respectively (Kumari et al., 2017). On the other hand the FTIR report for CES sample shows the peaks (Fig 2b) at $3463 \mathrm{~cm}^{-1}, 2881$ $\mathrm{cm}^{-1}, 2374 \mathrm{~cm}^{-1}$ represents $\mathrm{Si}-\mathrm{OH}, \mathrm{C}-\mathrm{H}, \mathrm{O}=\mathrm{C}=\mathrm{O}$ has broadened. More peaks at $1604 \mathrm{~cm}^{-1}, 1564 \mathrm{~cm}^{-1}, 1392$ $\mathrm{cm}^{-1}, 1118 \mathrm{~cm}^{-1}, 615 \mathrm{~cm}^{-1}$ represents functional groups $\mathrm{C}=\mathrm{C}, \mathrm{N}-\mathrm{O}, \mathrm{C}-\mathrm{H}, \mathrm{C}=\mathrm{O}$ and $\mathrm{C}-\mathrm{Cl}$ (Uddin et al., 2009; Chowdhury et al., 2011; Kumari et al., 2017). 


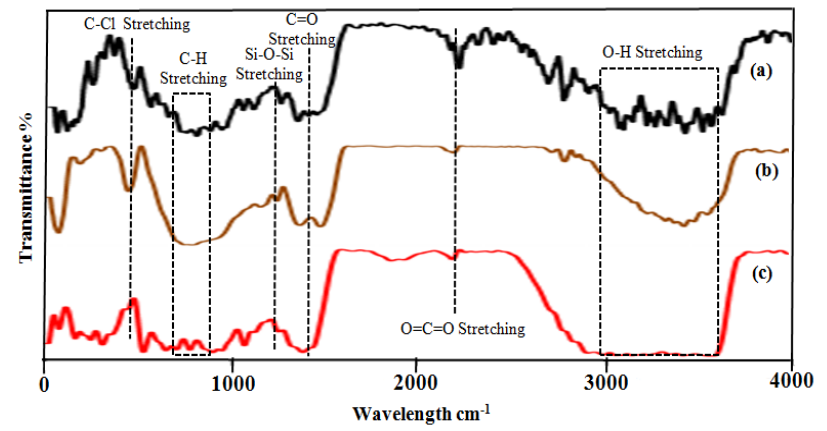

Fig 2: FTIR spectra of (a) RHA, (b) CES, and (c) ZRHA.

Whereas the spectra of Z-RHA sample (Fig 2c) shows the major peaks at $3363 \mathrm{~cm}^{-1}, 2374 \mathrm{~cm}^{-1}, 2137 \mathrm{~cm}^{-1}$, $1666 \mathrm{~cm}^{-1}, 1371 \mathrm{~cm}^{-1}, 887 \mathrm{~cm}^{-1}$ which represents $\mathrm{Si}$ $\mathrm{OH}, \mathrm{O}=\mathrm{C}=\mathrm{O}, \mathrm{N}=\mathrm{N}=\mathrm{N}, \mathrm{C}=\mathrm{O}, \mathrm{N}-\mathrm{O}, \mathrm{C}-\mathrm{Cl}$ functional groups respectively (Setthaya et al., 2017). The presence of the polar group on the surface of CES and Z-RHA is likely give the cation exchange capacity for both of them.

\section{XRD Analysis}

The XRD patterns of the RHA, CES and Z-RHA are shown in the Fig $\mathbf{3 a}, \mathbf{3 b}$, and $\mathbf{3 c}$ respectively. Both of the Fig 3a, and Fig 3b shows intense peaks at $23 \mathrm{~A}^{\circ}$ which are indicating the presence of carbon of the samples. As well as Fig $\mathbf{3 b}$ shows the intense peaks at $33 \mathrm{~A}^{\circ}$ due to the presence of the $\mathrm{SiO}_{2}$ in CES sample (Kumari et al., 2017). Consequently, XRD pattern for Z-RHA sample shows peaks at $25 \mathrm{~A}^{\circ}, 32 \mathrm{~A}^{\circ}$, and 35 $\mathrm{A}^{\circ}$ (Fig 3c) indicates presence of $\mathrm{AlO}_{2}$ and Zeolite $\left(\mathrm{Na}_{2} \mathrm{Al}_{2} \mathrm{Si}_{3} \cdot 3 \mathrm{O}_{10} \cdot 6\left(\mathrm{H}_{2} \mathrm{O}\right)_{7}\right)$ (Setthaya et al., 2017).

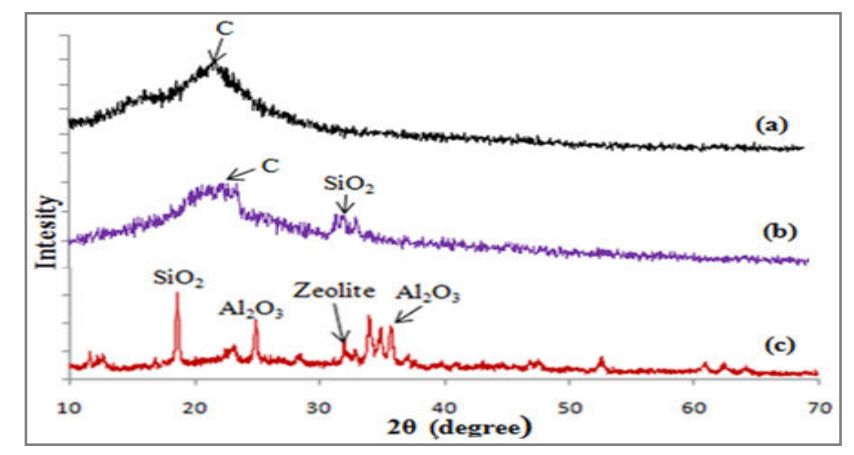

Fig 3: XRD patterns of (a) RHA, (b) CES, and (c) ZRHA.

\section{SEM, EDX and TEM Analysis}

Fig $4 \mathbf{a}, \mathbf{4 b}$, and $\mathbf{4 c}$ are showing the SEM images of RHA, CES and Z-RHA respectively. Surface structure UniversePG I www.universepg.com of the CES and Z-RHA are showing more porous than the RHA, which is evident for more adsorption of dyes by CES and Z-RHA rather than their parent materials RHA (Setthaya et al., 2017). From the BrunauerEmmett-Teller (BET) analysis it is also found that the surface area of the RHA, CES and Z-RHA are $28 \mathrm{~m}^{2} / \mathrm{g}$, $110 \mathrm{~m}^{2} / \mathrm{g}$ and $122 \mathrm{~m}^{2} / \mathrm{g}$ respectively.

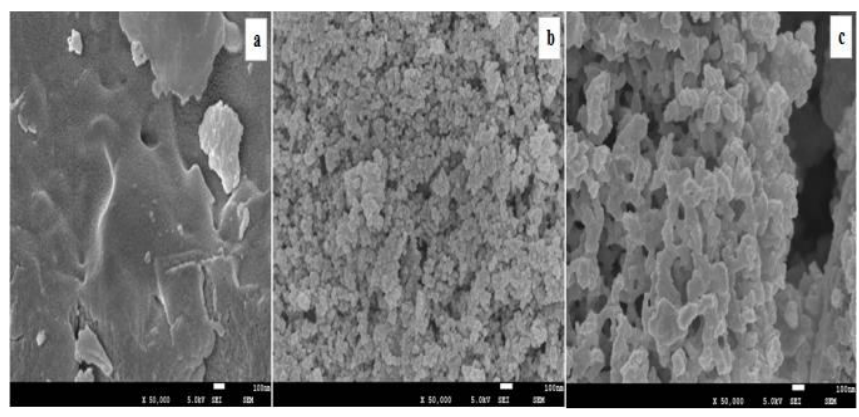

Fig 4: SEM images of (a) RHA, (b) CES, and (c) ZRHA.

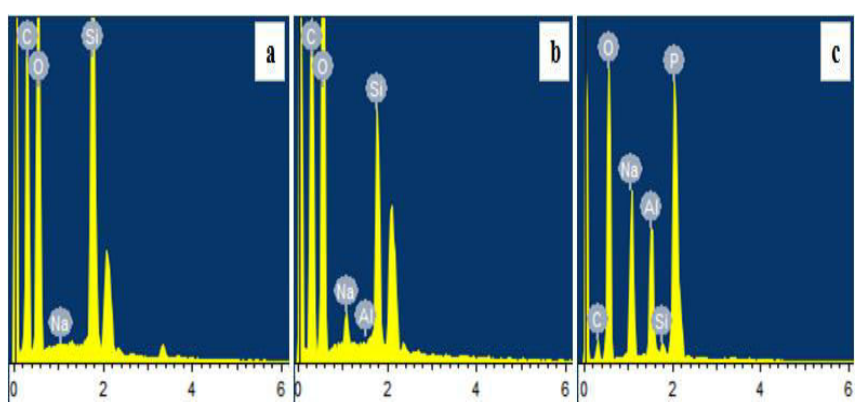

Fig 5: EDX spectra of (a) RHA, (b) CES, and (c) ZRHA.

In EDX analysis of the CES (Fig 5a) sample shows presence of more amount of silica than the RHA (Fig 4b). As well as Z-RHA sample (Fig 5c) shows the presence of $\mathrm{Al}$ which is evident for the presence of zeolite (Banerjee et al., 2017). Transmission electron microscopy (TEM) analysis was done to reveal the morphology of synthesized RHA, CES and Z-RHA (Fig 6).
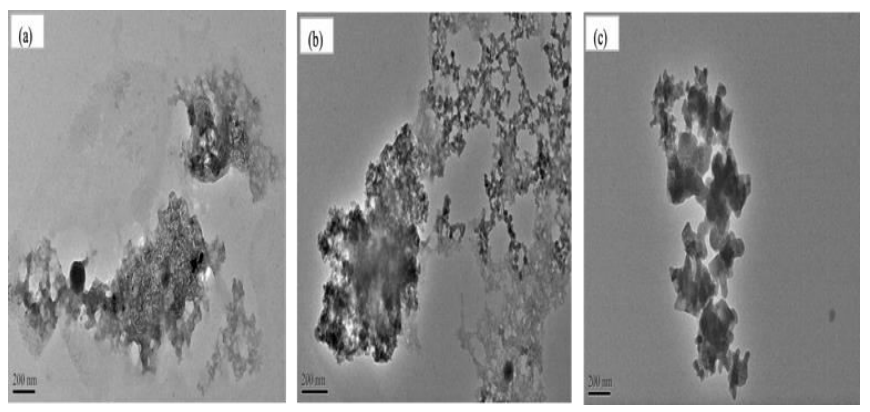

Fig 6: TEM images of (a) RHA, (b) CES, and (c) ZRHA. 
TEM micrograph of CES shows spherical in shape with smooth surface (Fig 6b), whereas the TEM image of Z-RHA shows rough surface of the adsorbent with higher surface area (Fig 6c).

\section{Determination of point of zero charge (PZC) of the} adsorbents - Surface charges of adsorbents play significantly important role in the adsorption process. To reveal the surface charges of a material, point of zero charge should be known. As the function of changing $\mathrm{pH}$ of the adsorbents the zeta potential of RHA, CES and Z-RHA were measured and plotted as shown in Fig 7. The PZC of the present materials are found 4.15, 4.21 and 4.34 respectively. This PZC indicate that all of the adsorbent materials containing negative charges at $\mathrm{pH}$ above PZC. Present zeta potential analysis is supported by later adsorption experiments, which shows that the material adsorbs cations on their surface due to the presence of negative charges.

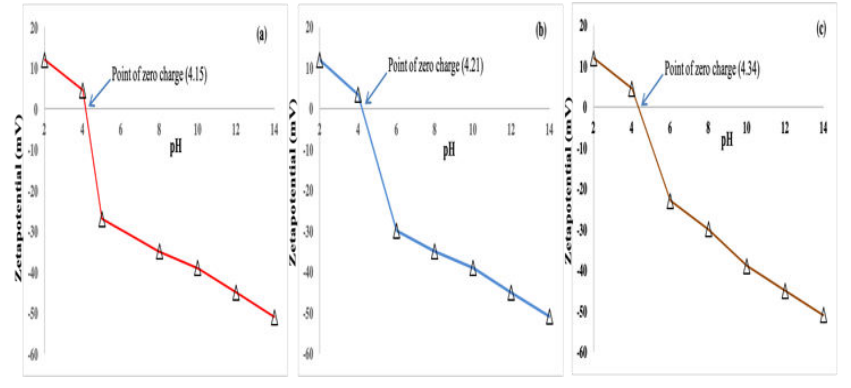

Fig 7: Point of zero charge (PZC) of synthesized adsorbents of (a) RHA, (b) CES, and (c) Z-RHA.

Effect of the initial concentrations of metal pollutants - The effect of the initial concentrations of metal solutions was investigated by altering the concentrations of effluent of 15, 30 and $50 \mathrm{ppb}$. The parameters like column diameter $(5 \mathrm{~cm})$, bed height $(15 \mathrm{~cm})$ and flow rate $(10 \mathrm{~mL} / \mathrm{min})$ were kept constant. Effect of the initial concentration of As (III) and As (V) has been plotted in the Fig 8. It was revealed that the adsorption capacity was getting higher with increasing the concentrations of the pollutants from 15 to $50 \mathrm{ppb}$. This phenomenon has been occurred due to raise of the driving force of adsorption with increasing concentrations gradient. Additionally, increasing concentrations of metal ions lead to higher driving forces to overcome mass transfer resistance in the liquid phase. Consequently, breakthrough time might

UniversePG I www.universepg.com be decreased with increasing the availability of the metal ions to bind with adsorbent sites (Palas et al., 2013).

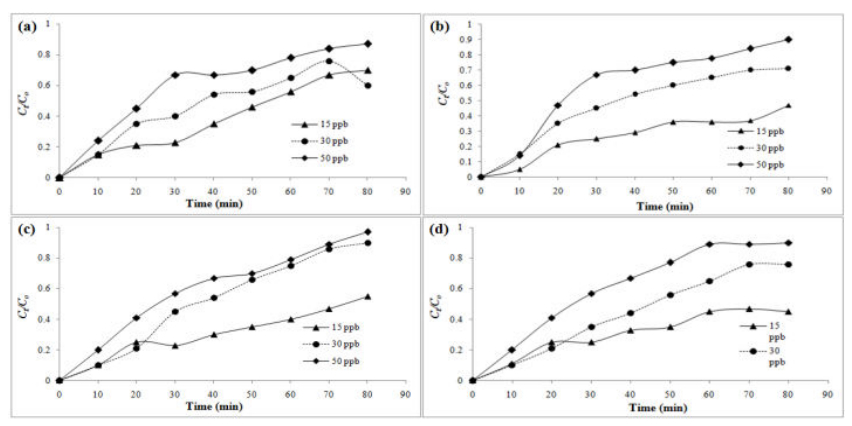

Fig 8: Effect of the initial concentrations of (a) As (III) removal by CES, (b) As (III) removal by Z-RHA, (c) As (V) removal by CES, and (d) As (V) removal by ZRHA.

Effect of height of the column - Effect on the adsorption of As (III) and As (V) onto rice husk mediated adsorbent CES and Z-RHA shown in Fig 9. For all cases it has been revealed that the increasing height of the column resulted more adsorption capacity of the adsorbents. An increase the bed height resulted in more contact time available for pollutants with adsorbents. This phenomenon might allow the pollutants to diffuse deeper into the adsorbents materials. Subsequently the percentages of arsenic removal for both adsorbents increased with increasing the height of the bed (Asif \& Chen, 2017).

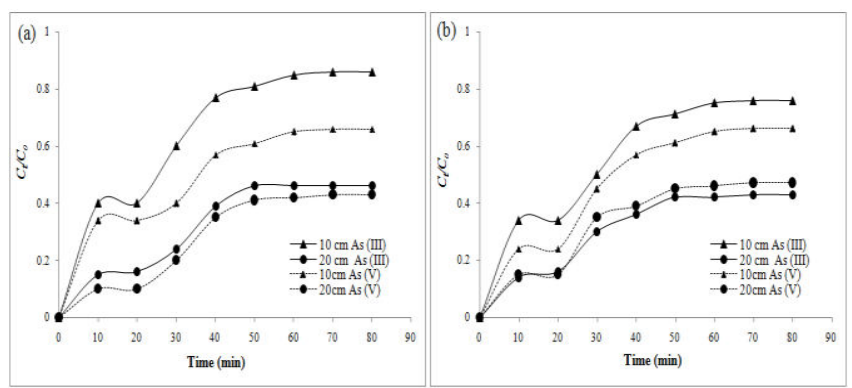

Fig 9: Effect of the height of the column to remove As (III) and As (V) by using (a) CES, and (b) Z-RHA.

Effect of diameter of the column - Fig 10 shows that, different removal efficiencies have been achieved for different diameter of the columns. The investigation to reveal the effect of the diameter in adsorption capacity has been done by keeping the constant initial concentrations (15ppb) of the metal solutions, constant flow rate $(7 \mathrm{~mL} / \mathrm{min})$, and constant height of the 46 
column $(10 \mathrm{~cm})$. It was revealed that the maximum removal percentage has been achieved for $5 \mathrm{~cm}$ diameter column for both of the metal pollutants and both of the adsorbents. The reason of the effect can be explained as that greater diameter allowing the metal ions to better adsorbed onto more available binding sites (Asif \& Chen, 2017).

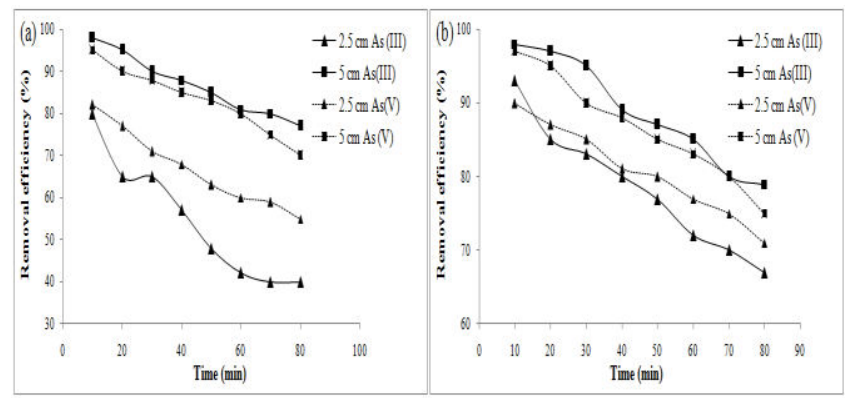

Fig 10: Effect of the diameter of the column on removal efficiencies of As (III) and As (V) by using (a) CES, and (b) Z-RHA.

Effect of the particle size of the adsorbents - The effect of the particle size of the adsorbents was observed in column by varying sizes of the particles of 25 mesh $(707 \mu \mathrm{m}), 20$ mesh $(841 \mu \mathrm{m})$ and 25 mesh $(1000 \mu \mathrm{m})$. In the investigation initial concentrations (15ppb) of the metal solutions, flow rate $(7 \mathrm{~mL} / \mathrm{min})$, and height of the column $(10 \mathrm{~cm})$ were constant. It was observed that the removal efficiency was increased with the decreasing particle size (Fig 11). Removal efficiency might be increased due to increasing surface area of the adsorbents particles and their compaction between particles. Adsorption process will be more efficient with the more available binding sites (Neeta and Jatinder, 2008).

\section{Sorption isotherm studies}

Langmuir isotherm - The Langmuir model was chosen to estimate the maximum adsorption capacity regarding the complete monolayer coverage of the surface of adsorbents (Igwe and Abia, 2006). Homogeneous adsorbent surface and equivalent sorption energies for each of the sorbent sites have been assumed for Langmuir isotherm model. Langmuir isotherm model usually describe the gas solid phase adsorption which assumes monolayer adsorption occur at definite localized sites.

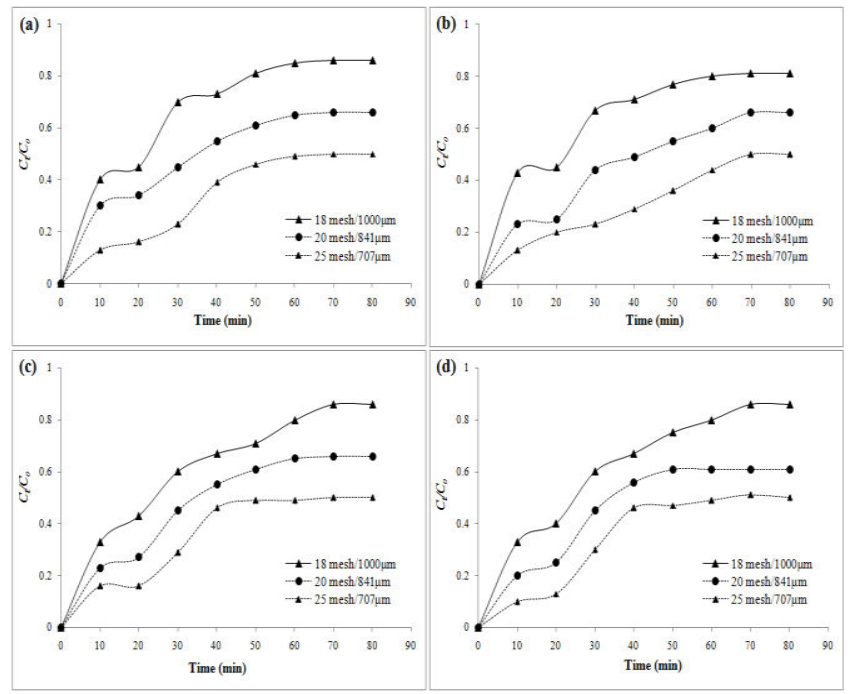

Fig 11: Effect of the particle size to remove (a) As (III) by using CES, (b)As (III) by using Z-RHA, (c) As (V) by using CES, and (d) As (V) by using Z-RHA.

This model supports homogenous adsorption including molecules with homogenous enthalpies and sorption activation energy. Langmuir isotherm model can be characterized by plateau and equilibrium saturation point and can be expressed as below (Langmuir, 1981):

$$
q_{e}=\frac{q_{\operatorname{maxk}_{L C}}}{\frac{1}{k_{L C_{e}}}}
$$

Where, $c_{e}$ is the concentration of As (III) at equilibrium stage and $k_{L}$ represents Langmuir constant. $q_{\max }$ is the monolayer capacity of the synthesized NPs. The constant $k_{L}$ and $q_{\max }$ can measure from the intercept and slope of the linear plot of $c_{e}$ and $c_{e} / q_{e}$ shown in Fig 12.

Table 1 shows the value of the parameters.

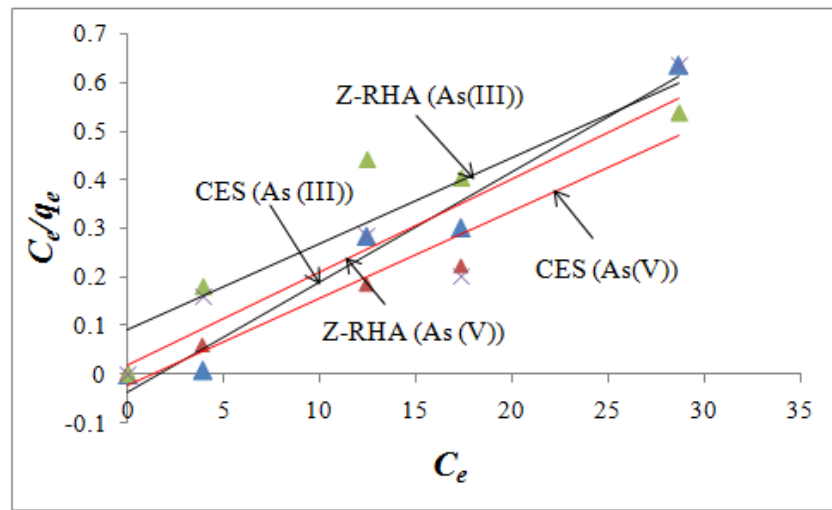

Fig 12: Langmuir adsorption isotherm of As (III) \& As (V) onto CES and Z-RHA. 
Table 1: Langmuir and Freundlich iostherm constants for As (III) and As (V) using Z-RHA and CES.

\begin{tabular}{|c|l|l|l|l|l|}
\hline Model & \multicolumn{1}{|c|}{$\begin{array}{c}\text { As } \\
\text { species }\end{array}$} & Adsorbents & \multicolumn{3}{|c|}{ Parameters } \\
\hline & & & $\begin{array}{l}\mathrm{Q}_{\max } \\
\mathrm{mg} / \mathrm{g}\end{array}$ & $\mathrm{R}_{\mathrm{L}}$ & $\mathrm{R}^{2}$ \\
\hline Langmuir & As (III) & Z-RHA & 85 & 0.79 & 0.987 \\
\hline & As (III) & CES & 89 & 0.82 & 0.991 \\
\hline & As (V) & Z-RHA & 77 & 0.81 & 0.988 \\
\hline & As (V) & CES & 79 & 0.80 & 0.976 \\
\hline & & & $1 / \mathrm{n}$ & $\mathrm{K}_{\mathrm{F}}$ & $\mathrm{R}^{2}$ \\
\hline Freundlich & As (III) & Z-RHA & 0.356 & 3.01 & 0.932 \\
\hline & As (III) & CES & 0.236 & 2.99 & 0.911 \\
\hline & As (V) & Z-RHA & 0.264 & 3.23 & 0.891 \\
\hline & As (V) & CES & 0.199 & 2.80 & 0.881 \\
\hline
\end{tabular}

Freundlich isotherm - Freundlich isotherm model generally describes the reversible and non-ideal adsorption. This model supports the multilayer adsorption over heterogeneous surface of the adsorbent (Beduoi et al., 2009). The surface heterogeneity or the adsorption intensity shown by the range of slope between 0 and 1 , i.e. the value close to zero means the surface is more heterogeneous. If the value of the adsorption intensity $(1 / \mathrm{n})$ is below 1 implies the chemisorptions process, whereas the value adsorption intensity above 1 indicating cooperative process. Freundlich isotherm model is describes by the following equation given bellow:

$$
q_{e}=k_{F} c_{e} 1 / n
$$

Where, $k_{F}$ notify the adsorption capacity. The isotherm type can assume by the value of $1 / \mathrm{n}$. If the value lies 0 $<1 / \mathrm{n}<1$, means that the isotherm is favorable. If the value is equal to 0 , it indicates the irreversible isotherm and the value greater than 1 means unfavorable isotherm. The value of $\mathrm{n}$ and $\mathrm{K}_{\mathrm{F}}$ had been taken from slope and intercept of the plot $\ln q_{e} \mathrm{vs} \ln c_{e}$ shown in Fig 13. Table 1 shows the value of the parameters.

\section{Sorption kinetic studies}

Adam-Bohart model - Adam-Bohart model has been applied to figure out the saturated concentrations of the adsorbate (Zhao et al., 2011).

$$
\frac{C t}{C o}=\exp \left(k_{A B} \operatorname{Cot}-k_{A B} N_{o} \frac{Z}{F}\right)
$$

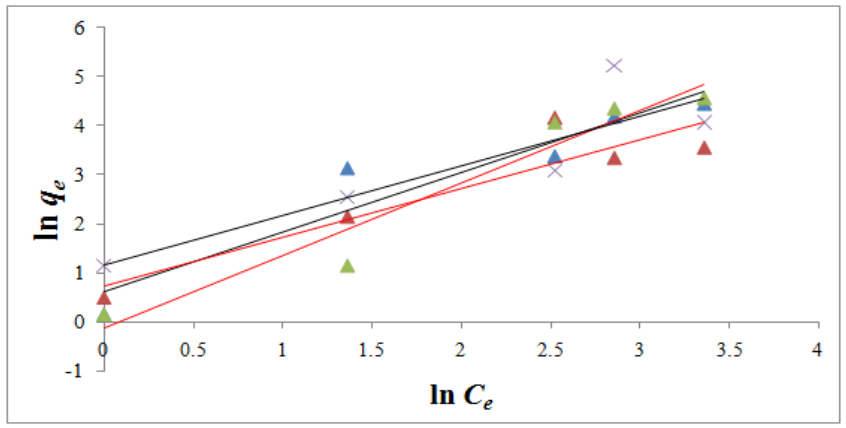

Fig 13: Freundlich adsorption isotherm of As (III) \& As (V) onto CES and Z-RHA.

Where, $\mathrm{k}_{\mathrm{AB}}(\mathrm{L} / \mu \mathrm{g} \cdot \mathrm{min})$ denotes kinetic constant, $\mathrm{F}$ $(\mathrm{cm} / \mathrm{min})$ represents the linear velocity, $N_{o}(\mu \mathrm{g} / \mathrm{L})$ represents the saturation concentrations, depth of the bed denoted by $\mathrm{Z}(\mathrm{cm})$, and $\mathrm{t}(\mathrm{min})$ denotes time. The values of $\mathrm{k}_{\mathrm{AB}}$ and $\mathrm{N}_{\mathrm{o}}$ have been determined from the intercept and slope of the plot $\ln \left(\mathrm{C}_{\mathrm{t}} / \mathrm{C}_{\mathrm{o}}\right)$ against time ( $\left.\mathrm{t}\right)$ (Fig 15). Table 2 shows the kinetic constants using Adam-Bohart model to remove both of As (III) and As (V) by using the manufactured adsorbents CES and ZRHA. From the Table 3 it is found that the range of the $\mathrm{R}^{2}$ ranged 0.787 to 0.991 for $15 \mathrm{ppb}, 30 \mathrm{ppb}$ and $50 \mathrm{ppb}$ concentrations of pollutants with remaining constant column diameter $(5 \mathrm{~cm})$, bed height $(15 \mathrm{~cm})$ and flow rate $\left(10 \mathrm{mLmin}^{-1}\right)$. It is observed that the values of $\mathrm{K}_{\mathrm{AB}}$ and $\mathrm{N}_{0}$ have no definite pattern when increasing the initial concentrations. From this phenomenon it can be conclude that the adsorption process of this part might be dominated by external mass transfer.

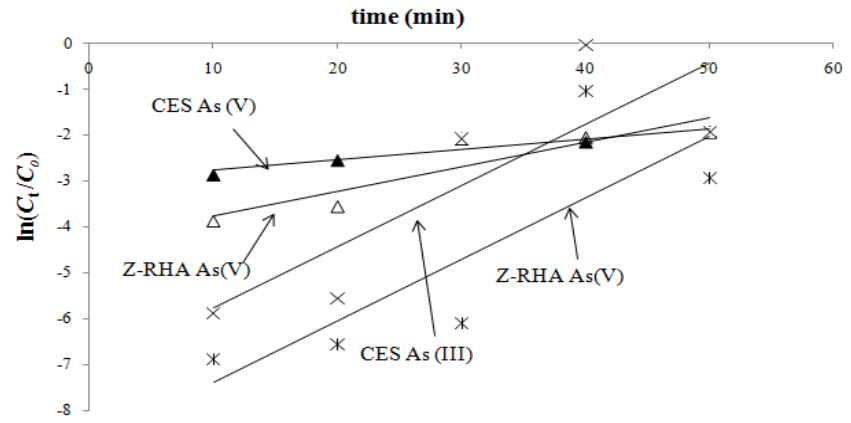

Fig 14: Adam-Bohart model for adsorption of As (III) and As (V) onto CES and Z-RHA.

Thomas model - Thomas model expresses as the following expression (Palas et al., 2013). Present expression was used here to find out the maximum adsorption capacity of rice husk mediated adsorbents for removing As (III) and As (V). 


$$
\frac{C t}{C o}=\frac{1}{1+\exp \left(K T H q_{o} \frac{m}{Q}-\mathrm{KTH}\right) C_{o} t}
$$

Where, $\mathrm{q}_{\mathrm{o}}(\mu \mathrm{g} / \mathrm{g})$ is the equilibrium As uptake per $\mathrm{g}$ ofrice husk mediated adsorbents, $m$ denotes mass of the adsorbents $(\mathrm{g})$, flow rate indicated by $\mathrm{Q}(\mathrm{mL} / \mathrm{min})$, $\mathrm{C}_{0}(\mathrm{ppb})$ and $\mathrm{Ct}(\mathrm{ppb})$ denotes initial and final concentrations of the pollutants respectively. Thomas model constant $\mathrm{K}_{\mathrm{TH}}$ and $\mathrm{q}_{\mathrm{o}}$ were calculated by linear regression analysis of the graphical plot of $\mathrm{Ln}\left(\mathrm{C}_{0} / \mathrm{C}_{\mathrm{t}^{-}}\right.$ 1) Vs time (t) (Fig 16). Table 3 presents the kinetic constants of Thomas model with varying different concentrations, and keeping constant column diameter $(5 \mathrm{~cm})$, bed height $(15 \mathrm{~cm})$ and flow rate $\left(10 \mathrm{mLmin}^{-1}\right)$. From the data of Table 2, shows that the variation in the initial concentrations of the pollutants affects the Thomas constant $\left(\mathrm{K}_{\mathrm{TH}}\right)$ rate and the equilibrium As uptake rate $\left(\mathrm{q}_{\mathrm{o}}\right)$. When the initial concentration of As (III) and As (V) increased from 15ppb to 50ppb the value of $\mathrm{K}_{\mathrm{TH}}$ decreased for both of the adsorbents, the value of $\mathrm{q}_{\mathrm{e}}$ increased. The regression coefficient $\left(\mathrm{R}^{2}\right)$ value was in the range of 0.779 to 0.976 .From these finding it might be says that, higher driving forces could be attributed to the higher concentrations of pollutants (Padmesh et al., 2005).

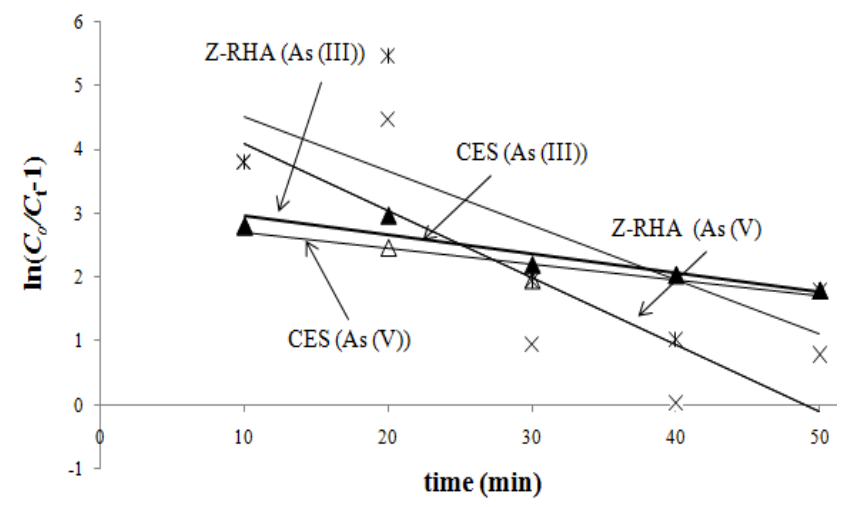

Fig 15: Thomas model for adsorption of As (V) onto CES and Z-RHA.

Yoon and Nelson model - Yoon and Nelson model was expressed on the base of the assumption, the probability of the decreasing rate of the adsorption of adsorbate molecules is proportional to the adsorbate adsorption and adsorbate breakthrough probability. Yoon and Nelson model can be expressed as follows (Zahra et al., 2013).

$$
\operatorname{Ln} \frac{C_{t}}{C_{o}-C_{t}}=K_{Y N} t-K_{Y N} T
$$

Where, $\mathrm{K}_{\mathrm{YN}}\left(\mathrm{min}^{-1}\right)$ is the model constant, $\mathrm{T}(\mathrm{min})$ is the time required for breakthrough. The value of the $\mathrm{K}_{\mathrm{YN}}$ and $\mathrm{T}$ were calculated from the intercept and slope of the linear plot Ln $\left(\mathrm{C}_{\mathrm{t}} / \mathrm{C}_{0}-\mathrm{C}_{\mathrm{t}}\right)$ Vs time (t) (Fig 17). Table 4 presents the kinetic constants of Yoon and Nelson model with varying different concentrations, and keeping constant column diameter $(5 \mathrm{~cm})$, bed height $(15 \mathrm{~cm})$ and flow rate $\left(10 \mathrm{mLmin}^{-1}\right)$. For both of the adsorbents it was found that the values of the $\mathrm{K}_{\mathrm{YN}}$ were increased with increasing the initial concentrations of As (III) and As (V). The linear regression coefficient $\left(\mathrm{R}^{2}\right)$ was in the range of 0.778 to 0.987 .

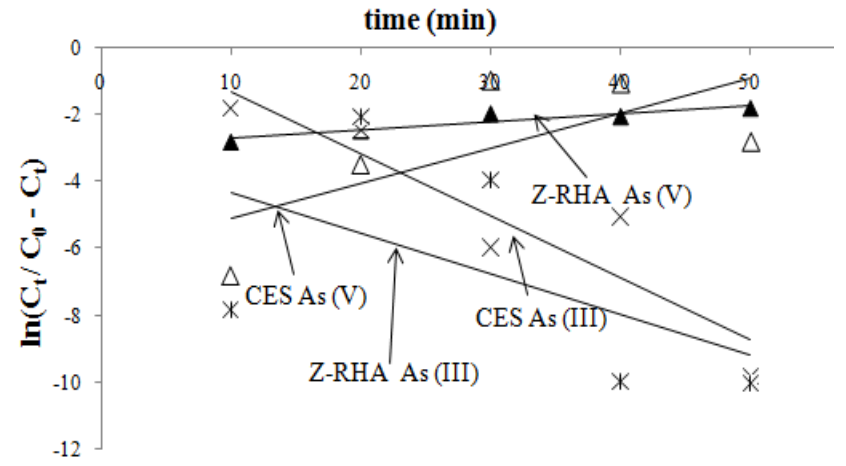

Fig 16: Yoon Nelson model for adsorption of As (V) onto CES and Z-RHA.

Table 2: Adam-Bohart model constants for different

\begin{tabular}{|c|c|c|c|c|c|}
\hline 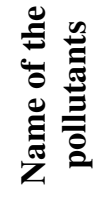 & 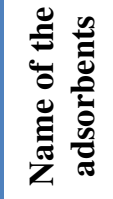 & $\underbrace{\frac{\hat{2}}{2}}_{0}$ & 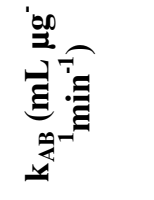 & है & 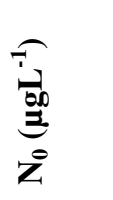 \\
\hline \multirow[t]{6}{*}{ As (III) } & CES & 15 & 0.000562 & 0.856 & 10.74 \\
\hline & & 30 & 0.000867 & 0.789 & 7.786 \\
\hline & & 50 & 0.000626 & 0.991 & 12.099 \\
\hline & Z-RHA & 15 & 0.00605 & 0.875 & 11.65 \\
\hline & & 30 & 0.000342 & 0.897 & 13.09 \\
\hline & & 50 & 0.000498 & 0.909 & 55.678 \\
\hline \multirow[t]{6}{*}{ As (V) } & CES & 15 & 0.00189 & 0.966 & 25.487 \\
\hline & & 30 & 0.000997 & 0.982 & 7.089 \\
\hline & & 50 & 0.000756 & 0.867 & 45.678 \\
\hline & Z-RHA & 15 & 0.00135 & 0.989 & 30.986 \\
\hline & & 30 & 0.000891 & 0.787 & 40.678 \\
\hline & & 50 & 0.000562 & 0.843 & 49.087 \\
\hline
\end{tabular}
concentrations of As (III) and As (V). 
Table 3: Thomas model constants for different concentrations of As (III) and As (V).

\begin{tabular}{|c|c|c|c|c|c|}
\hline 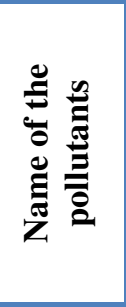 & 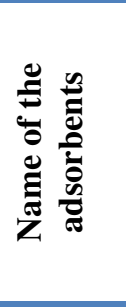 & $\widehat{\hat{\bar{E}}}$ & 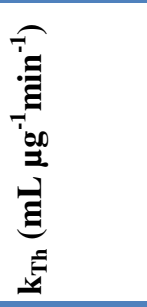 & \& & 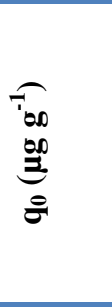 \\
\hline \multirow[t]{6}{*}{ As (III) } & \multirow[t]{3}{*}{ CES } & 15 & 0.00351 & 0.872 & 102.56 \\
\hline & & 30 & 0.00113 & 0.946 & 150.67 \\
\hline & & 50 & 0.00034 & 0.998 & 310.60 \\
\hline & \multirow[t]{3}{*}{ Z-RHA } & 15 & 0.00873 & 0.827 & 78.907 \\
\hline & & 30 & 0.00187 & 0.876 & 112.35 \\
\hline & & 50 & 0.00067 & 0.779 & 189.06 \\
\hline \multirow[t]{6}{*}{ As $(\mathrm{V})$} & \multirow[t]{3}{*}{ CES } & 15 & 0.00131 & 0.976 & 116.78 \\
\hline & & 30 & 0.00074 & 0.958 & 215.08 \\
\hline & & 50 & 0.00023 & 0.899 & 299.08 \\
\hline & \multirow[t]{3}{*}{ Z-RHA } & 15 & 0.000986 & 0.966 & 101.34 \\
\hline & & 30 & 0.000901 & 0.798 & 246.78 \\
\hline & & 50 & 0.000124 & 0.879 & 290.01 \\
\hline
\end{tabular}

Table 4: Yoon and Nelson model constants for different concentrations of As (III) and As (V).

\begin{tabular}{|c|c|c|c|c|c|}
\hline 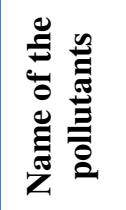 & 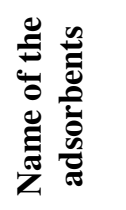 & & 茴 & $\begin{array}{l}\tilde{N} \\
\tilde{E}\end{array}$ & 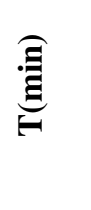 \\
\hline \multirow[t]{6}{*}{ As (III) } & \multirow[t]{3}{*}{ CES } & 15 & 0.0316 & 0.874 & 43.37 \\
\hline & & 30 & 0.0415 & 0.987 & 61.78 \\
\hline & & 50 & 0.0743 & 0.891 & 53.47 \\
\hline & \multirow[t]{3}{*}{ Z-RHA } & 15 & 0.0307 & 0.820 & 60.99 \\
\hline & & 30 & 0.0617 & 0.901 & 49.80 \\
\hline & & 50 & 0.0979 & 0.087 & 45.67 \\
\hline \multirow[t]{6}{*}{ As (V) } & \multirow[t]{3}{*}{ CES } & 15 & 0.0342 & 0.946 & 29.08 \\
\hline & & 30 & 0.0435 & 0.957 & 34.56 \\
\hline & & 50 & 0.0513 & 0.872 & 27.80 \\
\hline & \multirow[t]{3}{*}{ Z-RHA } & 15 & 0.0412 & 0.932 & 43.87 \\
\hline & & 30 & 0.0723 & 0.898 & 35.46 \\
\hline & & 50 & 0.0839 & 0.778 & 42.35 \\
\hline
\end{tabular}

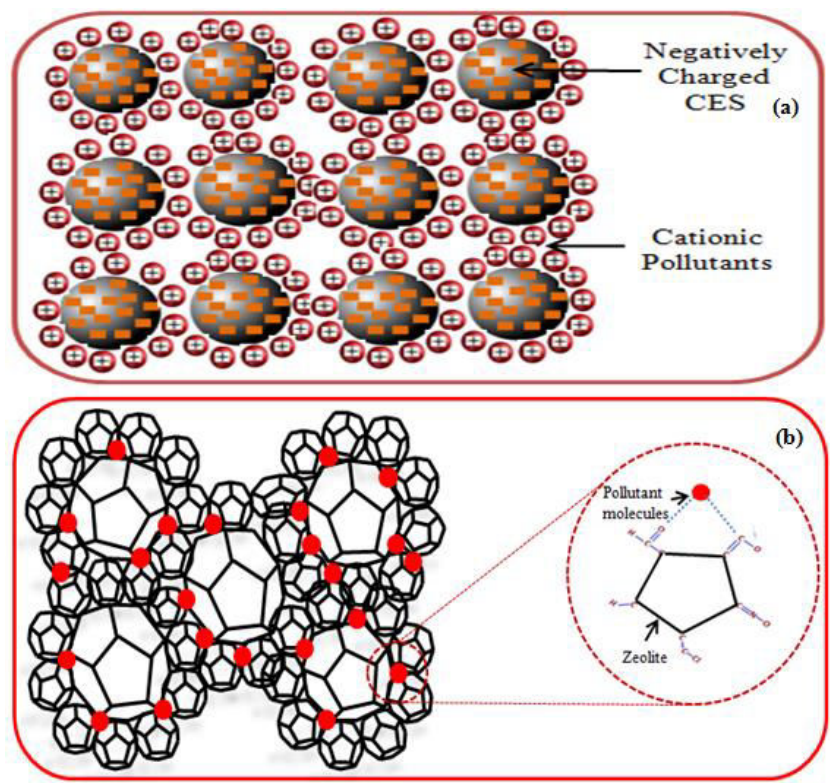

Fig 17: Proposed adsorption mechanisms of (a) CES, and (b) Z-RHA adsorbents.

According to the value of the regression $\left(\mathrm{R}^{2}\right)$ AdamBohart model found fittest with the present data of column adsorption (Table 2, 3, 4). It can be concluded that the monolayer adsorption occurred at definite localized sites of the adsorbents as well as the adsorption was homogenous with their homogenous enthalpies and sorption activation energy. An adsorption mechanism in this study has been proposed on the basis of findings of different kinetics models (Fig 17).

\section{Disposal of As treated rice husk}

Regeneration and reuse of the rice husk mediated adsorbents CES and Z-RHA is not feasible, as well as it is not cost effective (Verma et al., 2014). Consequently, to avoid the secondary pollution disposal of the arsenic concentrated rice husk adsorbents is another problem.

The adsorbents after treatment could be encapsulate through solidification and disposed in treated landfills (Leist et al., 2003). From the published literature there have different process of solidification. The most suitable process of solidification consider in present study concentrated arsenic incorporated into Portland cement. 


\section{CONCLUSION:}

Maximum removal efficiency of CES adsorbents for As (III) is $98 \%$ and for As (V) is $85 \%$, and of Z-RHA for As (III) is $95 \%$ and for As (V) is 92\%. The performances of the prepared adsorbents in column adsorption studies for As removal is much more higher in comparison with the other relevant adsorbents. After implying the data of column adsorption with different isotherm and kinetic models, it was found that AdamBohart model and Langmuir model was best fitted according to the value of the regression $\left(\mathrm{R}^{2}\right)$. Monolayer adsorption occurred at definite localized sites of the adsorbents as well as the adsorption was homogenous with their homogenous enthalpies and sorption activation energy. The proposed CES and ZRHA adsorbents fixed bed column treatment methods could be an easy alternate to remove arsenic species from water. Present method is easy and simple to handle and maintenance. This study shows the method could be efficient in wide ranges of the arsenic concentrations. Many of the countries of the world affected with arsenic contamination which could be solved by applying the fixed bed treatment methods. The effect of the different parameters to remove arsenic from the water also studied. The adsorbents after treatment can be incorporate with Portland cement by solidification. That's why no secondary pollution will be generated.

\section{ACKNOWLEDGEMENT:}

This work was supported by the State Key Laboratory of Environmental Criteria and Risk Assessment (SKLECRA2013FP12) and the Shandong Province Key Research and Development Program (2016GSF115040). The first author would also like to thanks for the financial support by the Chinese Scholarship Council, China (CSC No: 2016GXYO18).

\section{CONFLICT OF INTERESTS:}

The manuscript is solely contributed by the authors, there have no conflict of interest to declare.

\section{REFERENCES:}

1. Ali I, Peng C, Naz I, Khan ZM, Sultan M, Islam T, Abbasi IA (2017) Phytogenic mag- netic nanoparticles for wastewater treatment: a review. $R S C A d v, 7$ : 40158-40178.

https://doi.org/10.1039/C7RA04738J

2. Antonio ALS, SilviaJAC, Antonio JA. (2009). Emerging and innovative techniques for arsenic removal applied to a small water supply system. Sustain Water Manage, 1(4): 1288-1304. https://doi.org/10.3390/su1041288

3. Arenas CN, Vasco A, Betancur M, Martinez JD. (2017). Removal of indigo carmine (IC) from aqueous solution by adsorption through abrasive spherical materials made of rice husk ash (RHA). Process Safety Environ Prot, 106: 224-238.

\section{https://doi.org/10.1016/j.psep.2017.01.013}

4. Asif Z, Chen Z. (2017). Removal of arsenic from drinking water using rice husk. Appl Water Sci, 7: 1449-1458.

https://doi.org/10.1007/s13201-015-0323-X

5. Banerjee S, Barman S, Halder G. (2017). Sorptive elucidation of rice husk ash derived synthetic zeolite towards deionization of coalmine waste water: A comparative study. Ground water. Sust Dev. 5: 137-151.

https://doi.org/10.1016/j.gsd.2017.06.004

6. Beduoi A, Ahmadi MF, Bensalah N, Gadri A. (2009). Comparative study of Eriochrome black $\mathrm{T}$ treatment by BDD-anodic oxidation and Fenton process. Chem Eng J. 146: 98. https://doi.org/10.1016/j.cej.2008.05.029

7. Biterna M, Antonoglou L, Lazou E, Voutsa D. (2010). Arsenite removal from waters by zero valent iron: batch and column tests. Chemosphere, 78: 7-12.

https://doi.org/10.1016/j.chemosphere.2009.10.0 $\underline{07}$

8. Bundschuh J, Bhattacharya $\mathrm{P}$, Sracek O, Mellano MF, Ramırez AE, Storniolo AR, Martın RA, Cortes J, Litter MI, Jean JS. (2011). Arsenic removal from groundwater of the Chaco Pampean plain (Argentina) using natural geological materials as adsorbents. $J$ Environ Sci Health. 46(1): 1297-1310. https://doi.org/10.1080/10934529.2011.598838

9. Chowdhury S, Chakraborty S, Saha P. (2011). Biosorption of Basic Green 4 from aqueous 
solution by Ananas comosus (pineapple) leaf powder. Colloid Surface B. 84: 520-527. https://doi.org/10.1016/j.colsurfb.2011.02.009

10. Dinesh M, Charles U, Jr Pittman, (2007). Arsenic removal from water/wastewater using adsorbents. J Haz Mat. 142(1-2):2-53. https://doi.org/10.1016/j.jhazmat.2007.01.006

11. Garelick H, Dybowska A, Valsami-Jones E, Priest ND. (2005). Remediation technologies for arsenic contaminated drinking waters. $J$ Soil Sed, 5(3):182-185. https://doi.org/10.1065/jss2005.06.140

12. Goyal N, Barman S, BulasaraVK. (2005). Adsorptive removal of Biochanin $\mathrm{A}$, an endocrine disrupting compound, from its aqueous solution by synthesized zeolite $\mathrm{NaA}$. Des Water Treat, 1-11. https://doi.org/10.1080/19443994.2015.1108872

13. IgweJC, Abia AA. (2006). A bioseparation process for removing heavy metals from waste water using biosorbents. African J. Biotechnol 5(12): 1167-1179.

http://www.academicjournals.org/AJB

14. Islam T, Peng C, Ali I, Abbasi IA. (2018). Comparative study on anionic and cationic dyes removal from aqueous solution using different plant mediated magnetic nano particles. Ind J Geo Mar Sci. 47: 598-603. http://nopr.niscair.res.in/handle/123456789/4412 $\underline{4}$

15. KumariHJ, Krishnamoorthy P, Arumugam TK, Radhakrishnan S, Vasudevan D. (2017). An efficient removal of crystal violet dye from waste water by adsorption onto TLAC/ Chitosan composite: A novel low cost adsorbent. Int J BiolMacromol. 96: 324-333. https://doi.org/10.1016/j.ijbiomac.2016.11.077

16. Langmuir I. (1981). The adsorption of gases on plane surfaces of glass, mica and platinum. $J$ American Chem Society. 40:1361-1403. https://doi.org/10.1021/ja02242a004

17. Leist M, Casey RJ, Caridi D. (2003). The fixation and leaching of cement stabilized arsenic. Waste Manage. 23(4): 353-359. https://doi.org/10.1016/S0956-053X(02)00116-2

18. Li G., Sun G. X., Williams P. N., Nunes L., Zhu Y.G. (2011). Inorganic arsenic in Chinese food and its cancer risk. Environ. Int. 37(1): 1219-1225.

19. Moffat CD, Dominik JW, Arun S, Andrew JPW, Pascal S. (2014). Ramon, V. Molecular recognition and scavenging of arsenic from aqueous solution using dimetallic receptors. Chem A Europe J. 20(51): 17168-17177. https://doi.org/10.1002/chem.201404723

20. Mohan D, Pittman Jr CU. (2007). Arsenic removal from water/ wastewater using adsorbents-a critical review. J Haz Mat. 142: $1-53$.

https://doi.org/10.1016/j.jhazmat.2007.01.006

21. Neeta S, Jatinder S (2008) Removal of Zn ions from aqueous solution using rice (Oryza Sativa) husk in a sequential bed adsorption column. Int J Environ Tech Manage, 12(1): 944-951.

http://doi.org/10.1504/IJETM.2010.031537

22. Nurul-Amin $M$, Kaneco $S$, Kitagawa $T$, Begum A, Hideyuki KH, Suzuki T, Ohta K. (2006). Removal of arsenic in aqueous solutions by adsorption onto waste rice husk. Ind Eng Chem Res. 45: 8105-8110. https://doi.org/10.1021/ie060344j

23. Palas R, Naba KM, Shreya B, Biswajit D, Kousik D. (2013). Removal of arsenic (III) and arsenic (V) on chemically modified lowcost adsorbent: batch and column operations. Appl Water Sci. 3: 293-309. https://doi.org/10.1007/s13201-013-0082-5

24. PadmeshTVN, Vijayaraghavan K, Sekaran G, Velan M. (2005). Batch and column studies on biosorption of acid dyes on fresh water acro alga Azolla filiculoides. J Hazard Mater. 125(1-3): 121-129. https://doi.org/10.1016/j.jhazmat.2005.05.014

25. Saju JA, Rubel SNR, Rahman MM, Nayan SB, and Bagchi R. (2020). Effectiveness of manual bar screen in separating solid waste from municipal sewers of Khulna city, Aust. $J$. Eng. Innov. Technol., 2(3), 31-41. https://doi.org/10.34104/ajeit.020.031041

26. Scott F, Holly AM, Alexander VG. (2010). Spatial and temporal variations of groundwater arsenic in South and-Southeast Asia, Sci 
328(5982): 1123-1127.

http://doi.org/10.1126/science.1172974

27. Setthaya N, Chindaprasirt P, Yin S, Pimraksa K. (2017). TiO2-zeolite photocatalysts made of metakaolin and rice husk ash for removal of methylene blue dye. Powder Technol. 313: 417-426.

https://doi.org/10.1016/j.powtec.2017.01.014

28. Shelke VR, Bhagade SS, Mandavgane SA. (2010). Mesoporous silica from rice husk ash. Bull Chem React Engg Catal, 5: 63-67. http://bcrec.undip.ac.id/

29. Sohel N, Persson LA, Rahman M, Vahter M. (2009). Arsenic in drinking water and adult mortality a population-based cohort study in rural Bangladesh. Epidemio., 20(6): 824-830. http://doi.org/10.1097/EDE.0b013e3181bb56ec

30. Totlani K, Mehta R, Mandavgane SA. (2012). Comparative study of adsorption of Ni (II) on RHA and carbon embedded silica obtained from RHA. Chem Engg J. 181: 376-386. https://doi.org/10.1016/j.cej.2011.11.099
31. Uddin MT, Rukanuzzaman M, Khan MMR, Islam MA. (2009). Adsorption of methylene blue from aqueous solution by jackfruit (Artocarpus heteropyllus) leaf powder: A fixed-bed column study. J Environ Man, 90: 3443-3450. https://doi.org/10.1016/j.jenvman.2009.05.030

32. Verma P, Agarwal A, Singh VK. (2014). Arsenic removal from water through adsorption-a review. Rec. Res. Sci. Technol. 6(1): 219-226.

33. Zahra S, Reyhane S, Reza F (2013) Fixed-bed adsorption dynamics of $\mathrm{Pb}$ (II) adsorption from aqueous solution using nanostructured calumina. J Nanostructure Chem. 3(48): 21938865. https://doi.org/10.1186/2193-8865-3-48

34. Zhao G, Wu X, Tan WX. (2011). Sorption of heavy metal ions from aqueous solutions: a review. T O COLL S J, 4: 19-31. http://doi.org/10.2174/1876530001104010019

Citation: Islam T., and Peng C. (2020). Arsenic removal from aqueous solutions using carbon embedded silica and zeolite: column adsorption studies, Aust. J. Eng. Innov. Technol., 2(3), 42-53. https://doi.org/10.34104/ajeit.020.042053 (c) () 